\title{
A Portfolio Approach To Economic Development
}

\author{
Tam Bang Vu, University of Hawaii at Hilo, USA \\ Terrance Jalbert, University of Hawaii at Hilo, USA \\ David L. Hammes, University of Hawaii at Hilo, USA
}

\begin{abstract}
In this paper we introduce and empirically demonstrate a new model of economic development that we call Portfolio Economic Development. Our approach borrows from portfolio theory in finance and focuses on the risk-return nature of development projects. The paper examines how the loss of a dominant industry group from an island economy causes significant economic problems and how those problems might be mitigated by developing the economy in a portfolio context. The approach can help planners select optimal mixes of projects for development of any economy experiencing a transitional period.
\end{abstract}

Keywords: portfolio theory, economic development, output, employment

\section{INTRODUCTION}

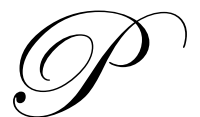

lanners in any economy going through a transitional period face a set of unique problems associated with economic development. Among these problems are barriers to obtaining resources, barriers associated with shipping products, labor movement problems, and environmental problems associated with the transport and manufacture of products.

These problems are exacerbated when the economy loses a major industry which may occur from time to time. In the case of Hawaii, the vast majority of the sugar industry was lost in the 1980s and 1990s due to changing competition in the sweetener market. The loss of a key industry such as agriculture on an island can occur not only because of new competition, but for many other reasons as well. ${ }^{1}$ Possibilities range from the presence of invasive species, e.g. fruit flies that restrict the export of crops from an area, to soil contamination or diseases that limit the ability to produce a product, to disruptions in the transportation of exported crops, and/or imports of necessary inputs, and so on. Implications of this analysis are not limited to agriculture. Loss of a dominant industry group can stem from the closing of a major manufacturing plant, exhaustion of natural resources, natural disasters, or other factors.

In this paper, we combine the concept of diversification in portfolio theory with that of development theory to create a model for any transitional economy. We then use data from the Hawaiian economy to demonstrate the usefulness of our theoretical model. The remainder of the paper is organized as follows: in section II we provide a literature review of modern portfolio theory and development theory. In section III we present a description of the economic situation facing any economy going through a transitional period and a portfolio approach to economic development. In section IV we develop a theoretical model reflecting this approach. Section V applies this model to the transitional economies and calibrates it using data from the Hawaiian economy as a demonstration. We end this paper with some conclusions and suggestions for further research in section VI. 


\section{LITERATURE REVIEW}

\section{Modern Portfolio Theory}

Modern portfolio theory was introduced by Markowitz (1952). Prior to this, a representative investor was assumed to focus on the risks and rewards of individual securities. In this view, investors would pick any asset yielding the highest reward with the least risk. Markowitz (1952) added uncertainty to the theory and developed a mathematical expression of diversification showing investors will select a portfolio based on the overall risk and reward of all assets instead of their individual characteristics. The efficient portfolio achieves an optimal balance of risk and reward.

Tobin (1958) extended Markowitz's theory by adding a risk free asset to the model. An investor who achieves an optimal balance between this risk free asset and the risky assets will obtain a super-efficient portfolio that outperforms the efficient portfolio. Sharpe $(1963,1964)$ refined Tobin's idea producing the capital asset price model (CAPM), where the expected return that an asset must offer relative to the risk free rate depends on the covariance of its return with the market portfolio. Sharpe concludes that all investors should hold some combination of the market portfolio and a risk-free asset. Levy and Markowitz (1979) develop a simple method for approximating the expected returns as the reward, and the volatility as the risk of a portfolio. Markowitz (1991) summarizes this method and calls for an extension of the computation to other state variables that we use in our paper.

Note that all the above papers focus on investors as opposed to consumers. In an effort to bring the portfolio theory to macroeconomics, Merton (1973) and Rubinstein (1976) expand Sharpe's idea to their consumption CAPM. The model yields similar results to the original CAPM, except that the consumers are concerned with the mean and variance of their consumption rather than those on their portfolio, that is, the expected return that an asset must offer relative to the risk free rate depends on the covariance of its return with consumption.

In an important paper, Lucas (1978) relates stochastic consumption and asset returns to output. Using a general utility function, he finds that the autocorrelation of asset returns are highly related to the stochastic characteristics of consumption. Imposing a strong assumption that all goods cannot be stored, that is, all goods are nondurables and aggregate consumption must equal aggregate output, he posits an argument that "all relevant information on the current and future physical state of the economy is summarized in the current output vector $y . " 2$

Hansen and Singleton (1983) extended Lucas's idea. Using a constant relative risk aversion utility function, they show-among other findings-that an increase in the variance of consumption would increase expected consumption growth, that is, a consumer will increase saving in the current time period so that she can increase consumption in the future, and consumption will become less smooth. Although their paper deals with a broader issue than intertemporal consumption, considering the papers by Lucas (1978), and Markowitz (1991) inspire us to develop a model for economies based on portfolio theory. ${ }^{3}$

\section{Modern Development Theory}

Prior to Simon Kuznets (1950), economic development 'theory' suggested that all countries should follow the same path of economic development experienced by the now developed countries. In this context industrialization was seen to be the most important stage. Kuznets (1950) showed that each developing country or region might need a distinct path of development. He also developed the first link between consumption and income that inspired Modigliani (1971) and Friedman (1957) to introduce their Life Cycle-Permanent Income Hypotheses.

Hall (1978) extends this hypothesis to the case of stochastic consumption for nondurable goods. This is an important step, as modern portfolio theory is based on the foundation of uncertainty. Mankiw (1982) adds the depreciation rate to develop a model for consumer durables expenditures. These two papers are crucial in laying the foundation for development theory that relates current consumption to future consumption (and so, current saving) in the income approach to development. 
Lewis (1954) emphasized the importance of capital accumulation for economic development. The HarrodDomar $(1939,1946)$ model requires increasing savings as a source of loanable funds for investment. Their theory is also in line with growth theory developed by Solow (1956) and refined by Swan (1956), in which saving is exogenous, or Ramsey's (1928) model, refined by Cass (1965), in which consumption (and saving) is endogenous.

In the meantime, Nurkse (1961) provides a theory of "balanced growth" that is further refined by Singer (1964). They argue that developing countries should diversify their output in an economy where all sectors grow instead of specializing into one-industry nations according to the theory of comparative advantage. Note that the term "diversification" in their context refers to a multi-industry economy instead of the risk-reward concept of the modern portfolio theory as discussed above. This fed a debate between the center-periphery theorists and the neoclassical theorists during 1960s through1990s period. The former such as Singer (1964) and Prebisch (1976) advocated government interventions so that the "periphery" developing countries can diversify and gain independence. The latter, including contributions from Bauer (1981) and Lal (1985), argue against government involvement as an obstructive force in the development process.

Also studying economic development are a series of papers investigating how volatility in growth affects the growth rate itself. Ramey and Ramey (1995) show that in the long run, a large variation in growth lowers the average rate of economic growth. Pritchett (2000) goes farther by examining developing and developed countries separately. He finds that volatility in growth of developing countries is six times greater than that of developed countries. This finding, in combination with Ramey and Ramey's results, implies that developing countries can enjoy higher average growth in the long run if they can reduce the variation in growth pattern and smooth the growth rate over time.

Regarding industrial policy, Acemoglu (1997) develops a seminal model to show the importance of diversification. Using an overlapping generation model of two periods with competitive markets and non-altruistic households, he assumes that different projects are imperfectly correlated so that there is safety in diversification. The results show that countries unable to diversify face greater uncertainty reducing their average growth rate. Hence, productivity and economic growth increase when the diversification opportunities improve. The results also show that in all cases the negative effects of indivisibilities are long lasting, although less so for developed countries where there are strong diminishing returns to capital.

In a recent paper, Mobarak (2005) extends the observations in Ramey and Ramey (1995) and Acemoglu (1997) by carrying out a thorough examination of the relationship between volatility and average growth. Using a simultaneous estimation approach on a two-equation model and data for eighty countries, he estimates not only the joint effects of volatility and growth on each other but also the joint determinants of average growth and volatility, including democracy, diversification, GDP per capita, trade, inflation and income distribution. Concerning the effects on average growth, he finds that volatility has a negative effect while democracy has a small but positive effect on mean growth. Regarding the effects on volatility, he shows that diversification and increases in GDP per capita both clearly reduce variation in growth rate, whereas greater trade, low inflation, and equitable distribution of income only weakly reduce volatility.

After the Asian financial crisis, the debate changed direction slightly to whether or not international organizations such as the World Bank and International Monetary Funds (IMF) should follow a one-size-fits-all approach. While Krugman (2001) argues that this approach is not helpful, Stiglitz (2002) emphasizes that they are downright harmful. They seem to go back to Kuznets's theory that each problem in the developing process needs to be addressed separately and diversification in industrial policy is crucial in hedging against any adversity in this process.

Our paper follows this direction where the specific problem is the need to restructure the economy from time to time. The paper discusses a case study of the sugar industry on the Big Island of Hawai'i in the late 1980s and 1990s and a federal/state government initiative, the RETA-H program, introduced to ease the transition from a major agricultural crop towards more economic diversification ${ }^{4}$. This allows us to set the stage for our portfolio model of economic development, showing its usefulness in cases wherever diversification may assist transitional economies. This discussion serves as an explanation for our theoretical model and our use of data for the Hawaiian economy in the empirical section. 


\section{TRANSITIONAL PERIODS IN AN ECONOMY AND A PORTFOLIO APPROACH TO ECONOMIC DEVELOPMENT}

\section{The Need for Restructuring in Economies}

Restructuring is called for in many countries, states, and communities whenever an economy is going through a transitional period. In the former socialist states of Eastern Europe, the transition from a single party rule to a multiple party rule and a planned economy to a market economy calls for a change from the mostly state enterprises to all other forms of production. The reform also redirects economies from heavy industrial to light, mixed, industry and services sectors. In less developed states such as Romania and Albania, there are also calls for restructuring in various agricultural sub-sectors as discussed in Martins and Ahrend (2003) and Bezemer (2006).

In the countries where one party rule is maintained, the redirection from planned economies to market economies also calls for the same restructuring. In Vietnam, Laos and Cambodia, the emphases are on a more diversified agricultural sector with more marketable crops such as coffee, rubber trees, teas, etc. replacing staple crops such as rice, corn, potatoes, etc, as analyzed in St John (2006). In China, where the state enterprises and heavy industry were dominant before its reform, the emphasis is on privatization and a redirection to light industry and services sectors. Even in an original market economy such as Thailand, economic reforms call for restructuring as discussed by its Department of Foreign Affairs and Trade (2000). A comparative study of the economic conditions in China and Vietnam, as well as the need for restructuring, is provided in Tang and Nhac (2002).

\section{Sugar on the Big Island of Hawai'i and the RETA Program}

During the late 1990s, many economic factors resulted in closure of the last commercial sugar growing and milling operations on the Big Island of Hawai' $i .{ }^{5}$ These operations comprised approximately 40,000 acres and directly employed upwards of 1000 people, a large loss given the relatively small size of the economy. ${ }^{6}$ Given the region's geography and the nature of the plantation-style operations, concerns arose as to what economic activity could take the place of sugar and sustain the communities affected. Dependence on sugar narrowed job skills. Division of labor led to employees specializing in various aspects of planting, growing, maintaining and irrigating, harvesting, transporting, and processing sugar. Employees knew one or two aspects of the entire process with little necessary formal education, implying that prospects for post-sugar employability in other industries on or off island, was unlikely.

In addition to the significant economic problems consequent upon the closing of the sugar industry, there were fears that strong social and cultural community ties would be broken as those of employable age migrated elsewhere leaving behind the elders and "hollowing out" the once-vibrant communities.

Various initiatives were taken in an attempt to re-utilize these lands including the RETA program. The program was designed mainly to smooth the transition from a sugar-based way-of-life to one based on more diversified economic alternatives. The program funded many agricultural projects. Indeed, the Big Island economy became quite vibrant. RETA was clearly an integral part of this recovery. One study finds that the present value of the real, economic contribution, of the RETA program to the state of Hawai'i's economy was between $\$ 737$ million and $\$ 2.33$ billion (2002) dollars (Hahn and Associates, 2002). Federal funding to support various projects represent attempts to support both crop diversification and sectoral diversification. The value to the state of further diversification is in the added stability of state employment and output that is possible with a more diversified product array.

All these restructuring activities push the economies in question in different directions during transitional periods where changing sectoral employment and unequal distribution of income is the norm. To reduce this unemployment volatility and income inequality, the state might seek to smooth out the output or the growth rate of output. The following section argues that diversification is the solution to this output smoothing approach to development. 


\section{A Portfolio Approach to Economic Development}

This section proposes a portfolio approach to economic development. The approach is based on the concept of diversification benefits. This diversification benefit is greater when returns from new products are inversely correlated with products already successfully being produced in an economy.

'Diversifying' by introducing a second product with the same, or very similar, production characteristics adds little if any benefits from reducing the variance of output. This is because the outputs from both products will be almost perfectly, positively, correlated. Instead, if the state diversifies by encouraging the production of a product (or products) whose output path is negatively correlated with another sector, the expected return might stay the same (or even drop slightly). However, variance of the aggregate output level would fall, perhaps significantly. This would represent a gain to the state in that employment and output variability would be reduced. This diversification across industries may be worthwhile even at the expense of lowering the steady-state path of state output available from complete specialization. ${ }^{7}$

In the short run, there is a tradeoff between growth and volatility. For one thing, smoothing output might mean producing less output thus incurring higher unemployment in the present. Hence, there are social welfare losses from structural unemployment and an increased tax burden in the short run. In the long run however, there are several reasons that the net return from lowering the variability of output may be positive.

As pointed out earlier, Ramey and Ramey (1995) and Mobarak (2005) show that larger variations in growth are associated with lower average rates of economic growth. This implies that reducing volatility helps maintain the average rate of growth in the long run. Additionally, the more stable the state's output level, the smaller on average other social programs will need to be relative to their size under a more variable output path. This is because added stability reduces the need and costs of expanding these programs dramatically in recessions (a 'peak load' problem) and the costs of having to contract them during times of expansion.

There is also a 'ratchet effect' to state programs. Once expanded, it is harder to reduce them to a more appropriate size when demand for services fall. Thus, the more variable output, the higher the steady-state level of state (or federal) government expenditures for programs aimed at assisting the victims of variability. Output stabilization would reduce this push towards ever-larger government expenditures.

The return to individuals of output smoothing may also be positive. Private moving costs can be substantial. In a climate of output variability and uncertainty, individuals have a higher average cost of job search and moving costs. These costs are certainly even higher on islands. Output smoothing reduces these costs. Output smoothing also allows tax-smoothing and it is well-known that the deadweight losses associated with tax smoothing are lower than the deadweight losses of a more variable pattern of taxation even when the present value of tax receipts raised is identical. ${ }^{8}$

Unfortunately, while risk-reduction, cost-savings, and tax-smoothing arguments may credibly be made for output smoothing through diversification, it is impossible to calculate these benefits by means other than inference. There are no state multipliers that capture these benefits.

\section{A PORTFOLIO DEVELOPMENT MODEL}

Our model is inspired by the papers discussed in the literature review section. First, the diversification concept in the development theory supports a multi-sector and multi-crop economy. Second, the diversification concept in the portfolio theory calls for a project in which an investor can achieve the optimal balance between the expected returns and the volatility of the project. Third, the consumption CAPM and asset pricing models transfer the investor problem to a consumer problem. Fourth, the issue of nondurable versus durable expenditures is resolved by using a more general model that can capture both goods. Finally, our model is for a social planner instead of a representative consumer, so the utility function is in a general form as in the Ramsey-Cass model to satisfy all consumers' preferences. Hence, the social planner seeks to: 
Maximize $E_{o} W=E_{o} \int_{t=o}^{\infty} e^{-\rho t} U_{t}\left[K_{t}\left(C_{t}\right)\right] d t$

subject to $\dot{A}_{t}=w_{t}-\dot{K}_{t}-\delta K_{t}+r A_{t}$

and $\dot{K}_{t} \equiv-\delta K_{t}+C_{t}$

where $\mathrm{E}_{\mathrm{o}} \mathrm{W}$ is the society's expected lifetime welfare at time zero, which is the expected utility of the society for as long as it shall exist at time zero, $U_{t}$ its instantaneous utility with the usual properties of $U^{\prime}>0$ and $U$ ' $<0$. Where $\mathrm{K}_{\mathrm{t}}$ is the stock of durable goods and $\mathrm{C}_{\mathrm{t}}$ the flow of durables expenditures, $A_{t}$ the social asset, $w_{t}$ aggregate wage income, $r$ the interest rate, $\rho$ the social time preferences, and $\delta$ is the depreciation rate. This is a combination of the Ramsey-Cass and Mankiw (1982) models. If the depreciation rate is one, then we return to the case for consumer nondurables and services as in Hall (1978).

Assuming that $\ln U^{\prime}(C)$ is normally distributed with mean $E_{o} \ln U^{\prime}(C)$ and variance $v$, the first order condition for the welfare maximization problem is: ${ }^{9}$

$E_{0} \frac{C_{t}}{C_{t}}=\frac{1}{\theta}\left(\frac{v}{2}+r-\rho\right)$, where $\theta=-\frac{U^{\prime \prime} C}{U^{\prime}}$

That is, $\theta$ is the agents' consumption elasticity of marginal utility, and $\frac{1}{\theta}=\phi$ is the agent's consumption elasticity of intertemporal substitution.

Thus, using a much more general model, we still come to similar result as in Hansen and Singleton (1983): the growth rate of consumption is higher the higher the consumption uncertainty. In other words, consumption becomes less smooth. However, Hansen and Singleton use a utility function of constant relative risk aversion form with $\mathrm{U}^{\prime \prime}>0$ to demonstrate the cautionary saving behavior by a certain group of consumers. ${ }^{10}$ Our utility is in a general form to cover all consumers. Hence, the increase in growth rate of consumption has to be interpreted in line with development theory, where an economy reduces consumption and targets a higher saving rate in the present time obtaining the loanable funds for investment and higher capital accumulation leading to greater output and consumption in the future.

Next, we follow Lucas (1978) and Romer (2003) to establish a relationship between consumption and output. Dissimilar to these two authors, our model involves both nondurable and durable goods; therefore, it is reasonable to assume that only a fraction of output is consumed, and the rest is saved for investment and capital accumulation, that is, for future consumption. Hence, we let

$C_{t}=\alpha Y_{t}$, where $\alpha$ is the marginal propensity to consume and $Y$ is output.

Assuming that in the long run equilibrium, the rate of social time preferences roughly equals the interest rate so that these two terms cancel out, we can rewrite Equation (4) as:

$E_{0} \frac{\dot{Y}_{t}}{Y_{t}}=\frac{1}{2 \theta} \sigma$, where $\sigma$ is the variance of the output. ${ }^{11}$ 
Differentiating both sides with respect to $\sigma$ yields:

$$
\frac{d E_{0} \frac{Y_{t}}{Y_{t}}}{d \sigma}=\frac{1}{2 \theta}>0, \text { as } \mathrm{U}^{\prime}>0 \text { and } \mathrm{U}^{\prime \prime}<0 \text {. }
$$

This implies that there is a positive correlation between the growth rate of output and its variance. Hence, a social planner who maximizes social welfare is facing a contemporary tradeoff between output growth and volatility. Since unemployment is negatively correlated to output growth, this also means that a social planner who maximizes social welfare is facing a contemporary tradeoff between low unemployment and volatility.

However, the dynamic nature of the model demands a long-term analysis as well. Since both terms on the right hand side of Equation (6) are positive, this equation implies that a society that sacrifices high output growth at present can enjoy a more stable pattern of growth in the future. Since Ramey and Ramey (1995) and Mobarak (2005) showed that a large variation in growth has a negative effect on the average rate of growth in the long run, this implies that the stability in growth eventually leads to higher average future growth. This, in relation to the above analysis, means that the sacrifice of a present rate of growth reduces future unemployment. Hence, a social planner who wishes to obtain steady growth in the future should try to reduce uncertainty by smoothing output growth. We can now state:

\section{Corollary 1}

In any economy, a social planner who wishes to maximize social welfare is facing a contemporary tradeoff between output growth and volatility. In the long run however, the planner should try to smooth out growth by reducing the variance of this output growth.

Returning to the transitional economies discussion, Acemoglu (1997) shows that diversification can increase the average growth rate, we need a diversification of outputs for a multi-sector and multi-crop economy, the social planner's problem is for the aggregate output across sectors and crops instead of each sector or each crop output. Additionally, since our model is derived from a combination of development theory and portfolio theory, we let this social project of many sectors and crops itself be a portfolio, and the aggregate output growth the portfolio's rate of return, henceforth called the portfolio return. Hence, we can state:

\section{Corollary 2}

In a transitional economy, a social planner who wishes to diversify in a portfolio approach to development should try to reduce the variance of portfolio return.

Reflecting on our argument in section III, a social planner in a transitional economy would rather have a low but steady growth of aggregate output than a high but volatile one. This steady portfolio return would guarantee a steady rate of employment while reducing the need and costs of expanding the state programs dramatically in recessions or contracting them during times of expansion. In other words, our model supports any program similar to RETA program for transitional economies in general and the Hawaiian economy in particular. Since Hansen and Singleton (1983) already carried out an empirical test of their consumption model and since our model is only a generalized version of theirs, we are more interested in demonstrating the usefulness of our model than testing our hypothesis. In the following section, we give a description of the data for the Hawaiian economy and our computations using these data. In so doing, we aim to demonstrate the usefulness of our model in helping the Hawaiian planner pick different projects based on certain target returns over time. 


\section{V: DATA AND COMPUTATION}

\section{Data}

To empirically examine the portfolio theory of economic development, annual data on the Gross State Product (GSP) of Hawaii were obtained from the Bureau of Economic Analysis. Data were collected both on the overall GSP of Hawaii and for each major industry operating within the state.

Data were collected for two sample periods. Data using the BEA's, NAICS methodology with chained 2000 dollars were collected for the period from 1997-2008. This methodology presents the data on a real basis. Data using the BEA's, SIC methodology with current dollars were obtained for the time period from 1963-1997. This methodology presents the data on a nominal basis. To obtain comparable results, the SIC data were converted to real figures using CPI-U data available from The Bureau of Labor Statistics.

The BEA switched from the SIC definitions of industry to NAICS industry definitions between 1997 and 1998. The two definitions use different methodologies and source data. The NAICS based methodology is consistent with Gross Domestic Product. The SIC based estimates are consistent with Gross Domestic Income (BEA 2005). The BEA specifically cautions against combining the two types of data together for analysis. No other dataset with SIC defined data for the time after 1997 and no data source with NAICS data prior to 1998 were available. Because of this limitation, the two datasets are analyzed separately. The SIC and NAICS methodologies classify the data into different industry groups. The SIC and NAICS industry segments examined are presented in Panel A and B of Table 1 respectively.

Table 1: Data Incorporated in the Study

This table presents the industries that were analyzed in this study. The first column indicates the industries examined and the second column indicates the proportion of the economy constituted by the industry. Panel B shows the data ranges for the two sources of data that were examined in this study.

\begin{tabular}{|l|l|}
\hline \multicolumn{1}{|c|}{ 1963-1997 (SIC Methodology) } & \multicolumn{1}{c|}{ 1997-2008 (NAICS Methodology) } \\
\hline Agriculture Forestry and Fishing & Agriculture, Forestry, Fishing, and Hunting \\
\hline Mining & Mining \\
\hline Construction & Utilities \\
\hline Manufacturing & Construction \\
\hline Transportation and Public Utilities & Manufacturing \\
\hline Wholesale Trade & Wholesale Trade \\
\hline Retail Trade & Retail Trade \\
\hline Finance Insurance and Real Estate & Transportation and warehousing, excluding Postal Service \\
\hline Services & Information \\
\hline Government & Finance and Insurance \\
\hline & Real estate, Rental, and Leasing \\
\hline & Professional and Technical Services \\
\hline & Management of Companies and Enterprises \\
\hline & Administrative and Waste Services \\
\hline & Educational Services \\
\hline & Health Care and Social Assistance \\
\hline & Arts, Entertainment, and Recreation \\
\hline & Accommodation and Food Services \\
\hline & Government \\
\hline
\end{tabular}

Tables 2 and 3 present summary statistics from the NAICS and SIC data respectively. The figure in each cell is the continuously compounded annual change in the level of economic activity in the sector for each year. For example Table 2 shows that in 1998 agriculture activity increased by 4.15 percent. The bottom of each table reports the average return, standard deviation of returns and the sector weightings for the most recent year analyzed. The highest one-year change in a sector in Table 2 is 19.96 for the management sector in 2002. The largest decline was 31.53 percent in agriculture in 2007 . The largest average return was 8.59 percent in the mining sector. The heaviest 
weightings in the economy in 2008 were government and real estate. Combined, these two sectors represent nearly 40 percent of the Hawaiian economy.

The SIC data paints a similar picture, however; SIC data show the service industry produced a slightly higher return than the mining industry. SIC data shows three sectors dominate the economy. Government along with the finance insurance and real estate sector and professional services sector represent about 66 percent of the economy.

Table 2: Summary Statistics NAICS Chained 2000 Dollars

This table presents summary statistics of the NAICS data in Chained 2000 Dollars. The figure in each cell is the continuously compounded change in the level of economic activity in the sector in percentage form. The average return is the arithmetic average return. The Standard deviation is the sample standard deviation. The 2008 weights are the weights of each sector in the economy in 2008 .

\begin{tabular}{|c|c|c|c|c|c|c|c|c|c|c|}
\hline & Ag. & Mining & Util. & Const. & Mfg. & Whsl. & Retail & Trans. & Info. & Fin Ins \\
\hline 1998 & 4.15 & 19.42 & -2.55 & -6.98 & -11.27 & 6.22 & -2.94 & -3.43 & 2.91 & -8.99 \\
\hline 1999 & 16.52 & 25.78 & 2.19 & -7.16 & 1.85 & 2.23 & 1.57 & 7.09 & 6.24 & -2.75 \\
\hline 2000 & 4.77 & 24.12 & -0.24 & 5.46 & -4.87 & -1.57 & 4.20 & 6.40 & 4.95 & 8.96 \\
\hline 2001 & -12.22 & 6.90 & -6.09 & -1.30 & -2.46 & 9.82 & 6.54 & 7.19 & 0.16 & 1.35 \\
\hline 2002 & 16.78 & -3.39 & -8.14 & 7.03 & 14.51 & 4.91 & 0.62 & -12.55 & -7.84 & 5.52 \\
\hline 2003 & -7.05 & 6.67 & 7.37 & 4.70 & -5.48 & 5.51 & 7.32 & -3.27 & 0.08 & -2.36 \\
\hline 2004 & -14.48 & -10.18 & -0.39 & -0.34 & -5.67 & 2.16 & 6.15 & 19.84 & 13.71 & 1.70 \\
\hline 2005 & 15.88 & -11.33 & -8.24 & 10.84 & -3.36 & 1.94 & 11.07 & 13.75 & 6.45 & 7.75 \\
\hline 2006 & -1.68 & 24.69 & 0.70 & -1.98 & 1.69 & -2.93 & 6.22 & 11.41 & 9.11 & 0.24 \\
\hline 2007 & -31.53 & 27.19 & 0.70 & -5.52 & 2.17 & 2.42 & 4.98 & 0.04 & 0.87 & -3.40 \\
\hline 2008 & -3.14 & -15.42 & 2.74 & -2.37 & -3.60 & 0.00 & 1.18 & -10.31 & -2.39 & -2.51 \\
\hline Avg. Ret. & -1.09 & 8.59 & -1.09 & 0.22 & -1.50 & 2.79 & 4.26 & 3.29 & 3.11 & 0.50 \\
\hline Std. Dev. & 15.00 & 16.54 & 4.82 & 6.00 & 6.63 & 3.66 & 3.88 & 10.11 & 5.88 & 5.33 \\
\hline $2008 \mathrm{Wt}$. & 0.005 & 0.001 & 0.015 & 0.042 & 0.016 & 0.036 & 0.096 & 0.049 & 0.032 & 0.041 \\
\hline & RE & Prof Sve & Mgt. & Adm & Edu & Hlth & Ent. & Acm. Food & Govt. & \\
\hline 1998 & -1.20 & 0.35 & -9.41 & -3.30 & -1.94 & 0.04 & -1.65 & -4.91 & -1.20 & \\
\hline 1999 & 2.58 & -2.27 & -9.59 & 5.45 & -3.74 & -1.49 & -5.72 & 0.48 & -0.73 & \\
\hline 2000 & -0.37 & 0.47 & -14.25 & 2.53 & 2.26 & 2.06 & -4.00 & 5.79 & -2.39 & \\
\hline 2001 & 0.93 & 4.86 & -4.51 & 2.72 & -4.05 & 1.24 & -1.03 & -4.43 & 0.86 & \\
\hline 2002 & -2.91 & 0.72 & 19.96 & 8.97 & -1.04 & 1.70 & 4.24 & 2.11 & 2.17 & \\
\hline 2003 & 4.22 & 8.90 & 2.94 & 13.46 & 7.54 & 5.21 & -1.39 & 4.81 & 1.37 & \\
\hline 2004 & 7.65 & 6.19 & 19.26 & -0.27 & 1.92 & 3.18 & 4.12 & 7.03 & 2.79 & \\
\hline 2005 & 8.26 & 6.90 & -16.40 & -0.61 & 0.24 & 5.31 & 3.96 & 3.08 & 1.46 & \\
\hline 2006 & 7.44 & 5.28 & -7.60 & 4.17 & 1.88 & 3.08 & 1.47 & 4.91 & 1.99 & \\
\hline 2007 & 5.72 & 3.97 & -8.22 & 2.69 & 2.30 & 0.37 & 2.16 & 0.02 & 1.48 & \\
\hline 2008 & -0.28 & 7.83 & -2.67 & 1.44 & 4.23 & 4.11 & 0.89 & -2.47 & 3.94 & \\
\hline Avg. Ret. & 2.91 & 3.93 & -2.77 & 3.39 & 0.87 & 2.25 & 0.28 & 1.49 & 1.07 & \\
\hline Std. Dev. & 3.96 & 3.61 & 12.24 & 4.66 & 3.45 & 2.17 & 3.34 & 4.12 & 1.84 & \\
\hline $2008 \mathrm{Wt}$. & 0.188 & 0.054 & 0.009 & 0.033 & 0.009 & 0.069 & 0.012 & 0.085 & 0.208 & \\
\hline
\end{tabular}


Table 3: Summary Statistics SIC Data in Current Dollars as Adjusted for Inflation

This table presents summary statistics of the SIC data in current dollars, as adjusted for inflation. The figure in each cell is the continuously compounded change in the level of economic activity in the sector in percentage form. The average return is the arithmetic average return. The Standard deviation is the sample standard deviations. The 1997 weights are the weights of each sector in the economy in 1997.

\begin{tabular}{|c|c|c|c|c|c|c|c|c|c|c|}
\hline & Ag & Mining & Const. & Mfg. & Trans & Whsl. & Retail & Fin Ins RE & Sve & Govt. \\
\hline 1964 & -11.67 & 21.02 & 14.42 & -2.78 & 9.50 & 2.34 & 11.31 & 12.90 & 9.35 & 6.10 \\
\hline 1965 & 5.69 & -23.91 & 12.51 & 5.60 & 12.68 & 5.85 & 6.81 & 14.52 & 7.71 & 5.41 \\
\hline 1967 & 3.25 & -2.82 & 11.84 & 3.46 & 12.14 & 5.14 & 6.79 & 1.90 & 9.14 & 4.54 \\
\hline 1968 & -8.32 & -3.04 & -7.22 & -2.61 & 7.18 & 3.86 & 7.39 & -1.14 & 8.89 & 5.82 \\
\hline 1969 & 0.44 & 18.21 & 14.44 & 7.33 & 13.39 & 6.72 & 7.71 & 2.63 & 7.89 & 8.10 \\
\hline 1970 & -6.06 & 28.33 & 26.46 & -0.42 & 6.35 & 5.22 & 7.85 & 16.01 & 12.51 & 2.61 \\
\hline 1971 & 0.94 & -5.56 & 10.79 & 8.79 & 4.24 & 3.97 & 8.33 & 7.61 & 6.32 & 6.06 \\
\hline 1972 & -0.85 & 9.06 & -12.92 & 0.68 & 9.75 & 0.49 & 4.49 & -0.50 & 8.38 & 5.57 \\
\hline 1973 & 6.49 & -16.51 & 4.25 & -8.13 & -0.61 & 5.76 & 7.89 & 2.22 & 11.15 & 8.06 \\
\hline 1974 & 9.29 & -21.45 & 14.79 & 2.51 & 3.40 & 3.83 & 6.54 & 9.82 & 8.68 & 2.37 \\
\hline 1975 & 2.36 & -51.01 & -1.30 & -2.33 & -1.85 & -5.35 & -2.69 & 11.26 & -2.14 & 1.70 \\
\hline 1976 & 10.19 & -100.00 & -1.35 & 22.69 & 1.26 & -6.91 & 7.91 & 8.38 & 4.62 & 2.20 \\
\hline 1977 & -25.93 & -5.60 & -14.64 & -15.09 & 8.21 & -0.33 & 7.67 & -15.27 & 8.18 & 3.93 \\
\hline 1978 & -6.77 & -6.30 & -0.36 & 3.98 & 4.35 & 5.45 & 3.62 & 5.78 & 8.01 & 0.39 \\
\hline 1979 & 3.83 & -7.32 & 4.23 & 0.02 & 3.08 & 0.62 & 5.14 & 10.15 & 4.56 & 0.21 \\
\hline 1980 & 10.80 & 89.25 & 7.95 & 7.90 & -5.34 & 0.80 & 1.74 & 8.31 & 3.94 & -3.82 \\
\hline 1981 & 25.59 & -12.66 & -4.72 & -8.97 & -0.21 & -7.10 & -3.97 & -0.46 & -0.66 & -1.15 \\
\hline 1982 & -40.54 & 30.73 & -11.62 & -9.82 & -1.81 & -1.85 & 0.47 & 4.33 & -0.16 & -0.49 \\
\hline 1983 & 0.73 & -5.98 & -18.38 & -6.71 & 1.37 & -3.66 & -0.68 & -0.87 & 5.12 & 3.68 \\
\hline 1984 & 4.77 & 25.61 & 6.66 & 8.55 & 4.77 & 4.48 & 5.99 & 9.86 & 5.96 & 2.56 \\
\hline 1985 & -1.27 & 36.32 & -7.39 & 0.97 & 5.28 & 6.11 & 6.05 & 5.13 & 7.03 & 7.80 \\
\hline 1986 & -6.73 & 11.92 & 7.81 & 5.02 & 3.74 & 2.44 & 3.58 & 5.89 & 5.02 & 1.99 \\
\hline 1987 & 13.10 & 60.06 & 14.75 & 1.94 & 9.38 & 3.43 & 3.97 & 8.49 & 6.26 & 0.98 \\
\hline 1988 & 1.24 & 3.83 & 9.54 & 4.08 & 7.71 & 1.20 & 7.63 & 3.21 & 6.72 & 0.36 \\
\hline 1989 & -1.62 & -4.05 & 12.95 & 3.82 & 7.48 & 16.51 & 8.59 & 3.48 & 8.37 & 1.13 \\
\hline 1990 & -2.11 & 25.83 & 19.49 & 10.76 & -0.40 & -3.74 & 7.39 & 5.48 & 6.79 & 2.52 \\
\hline 1991 & 5.06 & 13.84 & 11.80 & -10.27 & 3.16 & 4.50 & 4.66 & 13.28 & 9.02 & 0.69 \\
\hline 1992 & -10.27 & 37.86 & 3.10 & -1.55 & 5.07 & 0.23 & -3.53 & -1.61 & 2.75 & 3.24 \\
\hline 1993 & -3.99 & 7.86 & -5.35 & -2.31 & 0.89 & 0.33 & 1.19 & 1.63 & 2.17 & 5.55 \\
\hline 1994 & -8.04 & 2.05 & -0.75 & -16.83 & -6.38 & 0.45 & 0.86 & 1.70 & -0.67 & 0.14 \\
\hline 1995 & -1.88 & -7.53 & -12.72 & 1.42 & 2.94 & 1.24 & -0.08 & -3.20 & 1.63 & -3.73 \\
\hline 1996 & -6.76 & 2.21 & -11.53 & -5.90 & 5.24 & -3.76 & -1.10 & -2.66 & -0.56 & -2.69 \\
\hline 1997 & 0.84 & 10.75 & -12.37 & -0.25 & 0.37 & -0.79 & -0.85 & -2.35 & -0.70 & -2.41 \\
\hline Avg. Ret. & -1.16 & 4.35 & 2.28 & -0.02 & 4.02 & 1.63 & 4.05 & 4.34 & 5.36 & 2.39 \\
\hline Std. Dev. & 11.20 & 32.26 & 11.42 & 7.85 & 4.80 & 4.62 & 4.08 & 6.31 & 3.85 & 3.22 \\
\hline 1997 Wt. & 0.012 & 0.001 & 0.042 & 0.028 & 0.105 & 0.039 & 0.110 & 0.222 & 0.221 & 0.219 \\
\hline
\end{tabular}

\section{Computation}

The analysis begins by computing the weights of a risk-minimizing portfolio. Next, the weights for portfolios having various return levels are computed. Negative weights are not allowed in the analysis. While a state may eliminate a particular industry, it is unlikely that the state would sell-short an industry. ${ }^{12}$

The computations start by computing the natural $\log$ of the first difference, $l n$, of each variable, $R_{i}$, representing the rate of return, henceforth called the return, of a component in the economy. The computations are as follows where $L_{t}$ and $L_{t-1}$ are the current and previous year level of the variable respectively:

$$
R_{i}=\ln \left(\frac{L_{t}}{L_{t-1}}\right)
$$


The resulting continuously compounded returns for each economy component are weighted by the proportion of the economy represented by the component in the last sample year, $w_{i}$. This process calculates the overall return on the portfolio (economy) in each year, $R_{P, j}$ :

$$
R_{P, j}=\sum_{j=1}^{n} w_{i} * R_{i}
$$

Next, if $T$ is the number of years used in the analysis, the historical average $E\left(R_{P}\right)$ and sample standard deviation, $S_{P}$, of returns on the portfolio respectively can be computed as:

$$
\begin{aligned}
& E\left(R_{P}\right)=\sum_{i=1}^{T} R_{P, j} \\
& S_{P}=\sqrt{\frac{\left(R_{P, j}-E\left(R_{P}\right)\right)^{2}}{T-1}}
\end{aligned}
$$

The objective is to minimize the standard deviation for a given level of return on the portfolio by changing the proportion of the economy constituted by the various components. As noted earlier, the analysis here is limited to non-negative contributions by any given component. The problem is further limited such that the economy must be fully invested. Given this limitation, and denoting * as a predetermined desired return on the economy, the objective function and constraints are given as follows.

\section{Objective Function}

Minimize: $S_{P}$

$\underline{\text { Subject To: }}$

$E\left(R_{P}\right)=*$

$w_{i} \geq 0 \Lambda \mathrm{i}$

and

$\sum_{i=1}^{n} w_{i}=1$

The weighted standard deviation WTD STD is computed for comparison purposes. The weighted standard deviation is the theoretical standard deviation that would occur if the sectors were perfectly positively correlated. That is, if there were no diversification effects, the standard deviation would be WTD STD. Defining $S i$, as the standard deviation on sector $i$, the weighted standard deviation is computed as:

$W T D S T D=\sum_{i=1}^{n} w_{i} * S i$

The importance of properly weighting sectors in the economy can be determined by examining the amount of risk eliminated because of diversification. We compute the proportion of risk eliminated due to diversification effects, $R S K R E D$ as follows:

$R S K R E D=1-\left(\frac{S p}{W T D S T D}\right)$ 
The resulting optimal component weightings in the economy are presented in Tables 4-7. Table 4 and 5 examine NAICS data. Tables 6 and 7 examine SIC data. The methodology used in Tables 4 and 6 place no restrictions on weightings assigned to an economic sector. There are certain practical limitations that apply to the results presented in Tables 4 and 6. It is not likely that certain sectors, such as retail, could be eliminated from the economy entirely. To address this issue and provide a more practical result, the methodology in Tables 5 and 7 limits the weighting of any sector to 50 percent of its current weighting. Thus, a sector can only be reduced to $50 \%$ of its most recent level. For each table, the portfolio optimizing computations are completed for a number of returns indicated in the left hand column as well as for the risk-minimizing portfolio. The figure in each cell is the weighting assigned to the sector to achieve the desired return. In the right-most three columns, the standard deviation, weighted standard deviation and risk reduction percentage are reported. Table 4, Panel A shows portfolio returns ranging from -2 percent to 8 percent are theoretically possible. For the minimum variance portfolio, 88 percent of total risk was eliminated as a result of diversification effects. The minimum risk portfolio produced a return of 1.561 percent with a standard deviation of 0.51 percent.

Next, we examine how the optimal allocation of the economy changes when a given industry is eliminated from the economy. The probability of a shock to the economy occurring is not clear and difficult to estimate. Moreover, the impact that any particular shock would have on various economic sectors is not clear and difficult to estimate. To approximate this effect a shock is introduced that eliminates an entire sector from the economy. To determine how such a loss affects the optimal sectoral allocation in the economy, an additional constraint is imposed forcing the agriculture sector weighting equal to zero. In the model, this implies that the island will no longer be able to produce agricultural products. Such an event could occur for instance if the soil were to become contaminated or unusable due to a volcanic eruption or if disease or pests were to render the growth of crops impossible.

If $w_{a g}$ is the proportion of the economy resulting from agriculture, the additional constraint can be mathematically expressed in the above model as $w_{a g}=0$. The resulting optimal weightings are presented in Panel B of Table 4. The results show the agriculture loss causes a redistribution of weightings across the remaining sectors: The professional services weighting declined while weightings for the information, wholesale and finance sectors increased. Interestingly for some returns the government sector is assigned a weighting of zero, a result some of our friends would certainly cheer yet raises the question of who employs the social planner(s)?

In a Richard Roll (1977) sense, the elimination of any sector from the economy will reduce risk elimination possibilities. This occurs because of a resulting forced specialization. To determine the diversification potential that is lost with the elimination of a sector, we compare the risk reduction in Panels A and B of Table 4. The risk reduction lost with the elimination of a sector ranges from four percent at higher levels of return to 87 percent for a 1 or 2 percent return for Panel A and 4 to 82 percent for Panel B. At each level of return, the amount of risk that can be eliminated is higher when agriculture is a component of the economy. It is important to note the finding of no risk reduction for returns above four percent is not a generalized result. The absence of risk reduction in this case occurs because the original weightings at returns above two percent did not include the agriculture sector. Note that the standard deviation increases substantially for returns above 2 percent, nearly doubling for each additional percent of return in some instances. Relating this to our theoretical model and the corollary 2, this suggests that the social planner should target a 2 percent real growth rate.

In the above analysis, sectoral weightings can take on any non-negative value. As noted above, there are certain practical limitations to such a scenario. While the return optimizing weightings might argue for the elimination of retail as a sector of the economy, elimination of the retail sector in its entirety would certainly not be a feasible solution. To address this issue, the following analysis limits the reduction of any component to $50 \%$ of its current level. Fifty percent is arbitrarily selected to demonstrate how such a limitation affects the overall allocation. It is possible that some sectors of the economy could be reduced below 50 percent of their current level, while others could be reduced by a smaller amount. Analyzing the precise extent to which various sectors of the economy could be eliminated is beyond the scope of this paper. If $W_{i, c}$ is the most recent allocation within the economy, the additional restriction in the above problem can be mathematically stated as: $W_{i} \geq W_{i, c} * 0.5$. 


\section{Table 4: NAICS Real Data Unrestricted Model}

This table shows the risk-minimizing combination of sector weightings that produce various levels of returns. In this table weightings are allowed to take any value. NAICS real data from 1998-2008 are examined. M indicates the minimum variance portfolio. SP indicates the standard deviation on the portfolio. Wt. is the theoretical standard deviation that would occur if each of the sectors were perfectly positively correlated. Red. is the proportion of risk that was eliminated due to portfolio effects. Panel A shows the optimum weightings considering all sectors currently in the economy. Panel B presents the optimal weightings when agriculture is eliminated as a candidate sector. The expected return on the minimum variance portfolio in Panel A is 1.561 percent. The expected return on the minimum variance portfolio in Panel B is 1.794 percent.

\begin{tabular}{|c|c|c|c|c|c|c|c|c|c|c|c|c|c|c|c|c|c|c|c|c|c|c|c|}
\hline \multicolumn{24}{|c|}{ Panel A: Unrestricted Model with All Industries } \\
\hline \multirow{14}{*}{ 苞 } & & \multicolumn{19}{|c|}{ 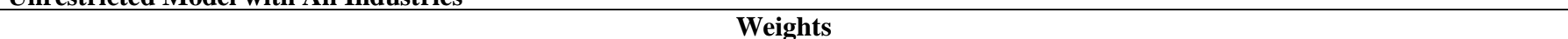 } & \multicolumn{3}{|c|}{ Std Dev } \\
\hline & & Ag & Min & Util & Cns & Mfg & Wh & Reta & Tra & Info & Fin & RE & Sve & Mgt & Ad & Edu & HIt & Ent & Aco & Gov & Sp & Wt & Red \\
\hline & $\mathrm{M}$ & 0.03 & 0.05 & 0.09 & 0.00 & 0.00 & 0.19 & 0.00 & 0.00 & 0.04 & 0.07 & 0.00 & 0.00 & 0.00 & 0.00 & 0.00 & 0.07 & 0.10 & 0.00 & 0.32 & 0.51 & 4.314 & 0.88 \\
\hline & - & 0.07 & 0.00 & 0.28 & 0.00 & 0.12 & 0.00 & 0.00 & 0.00 & 0.00 & & 0.00 & 0.00 & 0.51 & 0.00 & 0.00 & 0.00 & 0.00 & 0.00 & 0.00 & 6.60 & 9.596 & 0.31 \\
\hline & - & 0.07 & 0.00 & 0.50 & 0.00 & 0.20 & 0.00 & 0.00 & 0.00 & 0.00 & & 0.00 & 0.00 & 0.04 & 0.00 & 0.00 & 0.00 & 0.17 & 0.00 & 0.00 & 2.39 & & 0.60 \\
\hline & 0 & 0.05 & 0.00 & 0.36 & 0.00 & 0.05 & 0.13 & 0.00 & 0.01 & 0.00 & 0.08 & 0.00 & 0.00 & 0.00 & 0.00 & 0.00 & 0.00 & 0.30 & 0.00 & 0.00 & 1.16 & & 0.76 \\
\hline & 1 & 0.04 & 0.03 & 0.20 & 0.00 & 0.00 & 0.19 & 0.00 & 0.00 & 0.02 & 0.09 & 0.00 & 0.00 & 0.00 & 0.00 & 0.00 & 0.00 & 0.22 & 0.00 & 0.17 & 0.59 & 4.723 & 0.87 \\
\hline & 2 & 0.03 & 0.06 & 0.00 & 0.00 & 0.00 & 0.19 & 0.00 & 0.00 & 0.06 & 0.04 & 0.00 & 0.00 & 0.00 & 0.00 & 0.06 & 0.10 & 0.00 & 0.00 & 0.42 & 0.51 & & 0.87 \\
\hline & 3 & 0.05 & 0.09 & 0.00 & 0.00 & 0.00 & 0.19 & 0.00 & 0.00 & 0.05 & 0.0 & 0.00 & 0.35 & 0.01 & 0.00 & 0.00 & 0.00 & 0.00 & 0.00 & 0.19 & 0.89 & 416 & 0.83 \\
\hline & 4 & 0.06 & 0.12 & 0.00 & 0.00 & 0.00 & 0.16 & 0.01 & 0.00 & 0.00 & 0.0 & 0.00 & 0.62 & 0.00 & 0.00 & 0.00 & 0.00 & 0.00 & 0.00 & 0.00 & 1.54 & & 0.74 \\
\hline & 5 & 0.00 & 0.22 & 0.00 & 0.00 & 0.00 & 0.00 & 0.13 & 0.00 & 0.00 & 0.00 & 0.00 & 0.64 & 0.00 & 0.00 & 0.00 & 0.00 & 0.00 & 0.00 & 0.00 & 3.15 & .516 & 0.51 \\
\hline & 6 & 0.00 & 0.43 & 0.00 & 0.00 & 0.00 & 0.00 & 0.15 & 0.00 & 0.00 & 0.00 & 0.00 & 0.40 & 0.00 & 0.00 & 0.00 & 0.00 & 0.00 & 0.00 & 0.00 & 6.42 & 9.279 & 0.30 \\
\hline & 7 & 0.00 & 0.64 & 0.00 & 0.00 & 0.00 & 0.00 & 0.18 & 0.00 & 0.00 & 0.00 & 0.00 & 0.16 & 0.00 & 0.00 & 0.00 & 0.00 & 0.00 & 0.00 & 0.00 & 10.2 & 12.036 & 0.14 \\
\hline & 8 & 0.00 & 0.86 & 0.00 & 0.00 & 0.00 & 0.00 & 0.13 & 0.00 & 0.00 & 0.00 & 0.00 & 0.00 & 0.00 & 0.00 & 0.00 & 0.00 & 0.00 & 0.00 & 0.00 & 14.2 & 14.846 & 0.04 \\
\hline
\end{tabular}

Panel B: Unrestricted Model Excluding Agriculture

\begin{tabular}{|c|c|c|c|c|c|c|c|c|c|c|c|c|c|c|c|c|c|c|c|c|c|c|c|}
\hline & & \multicolumn{19}{|c|}{ Weights } & \multicolumn{3}{|c|}{ Std Dev } \\
\hline & & $\mathrm{Ag}$ & Min & Util & Cns & Mfg & Wh & Reta & Tra & Info & Fin & RE & Sve & Mgt & Ad & Edu & Hlt & Ent & Aco & Gov & Sp & Wt & Red \\
\hline \multirow{12}{*}{ 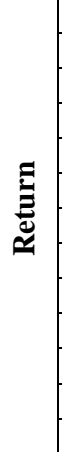 } & $\mathrm{M}$ & 0.00 & 0.05 & 0.08 & 0.00 & 0.00 & 0.20 & 0.00 & 0.00 & 0.04 & 0.09 & 0.00 & 0.00 & 0.00 & 0.00 & 0.00 & 0.16 & 0.07 & 0.00 & 0.27 & 0.70 & 3.920 & 0.82 \\
\hline & - & 0.00 & 0.00 & 0.29 & 0.00 & 0.20 & 0.00 & 0.00 & 0.00 & 0.00 & 0.00 & 0.00 & 0.00 & 0.49 & 0.00 & 0.00 & 0.00 & 0.00 & 0.00 & 0.00 & 6.74 & 8.887 & 0.24 \\
\hline & - & 0.00 & 0.00 & 0.50 & 0.09 & 0.27 & 0.00 & 0.00 & 0.00 & 0.00 & 0.00 & 0.00 & 0.00 & 0.03 & 0.00 & 0.00 & 0.00 & 0.08 & 0.00 & 0.00 & 2.60 & 5.543 & 0.53 \\
\hline & 0 & 0.00 & 0.00 & 0.36 & 0.00 & 0.08 & 0.13 & 0.00 & 0.00 & 0.00 & 0.15 & 0.00 & 0.00 & 0.00 & 0.00 & 0.00 & 0.00 & 0.25 & 0.00 & 0.00 & 1.37 & 4.521 & 0.69 \\
\hline & 1 & 0.00 & 0.03 & 0.20 & 0.00 & 0.02 & 0.21 & 0.00 & 0.00 & 0.03 & 0.15 & 0.00 & 0.00 & 0.00 & 0.00 & 0.00 & 0.00 & 0.16 & 0.00 & 0.18 & 0.83 & 4.299 & 0.80 \\
\hline & 2 & 0.00 & 0.05 & 0.03 & 0.00 & 0.00 & 0.18 & 0.00 & 0.00 & 0.04 & 0.08 & 0.00 & 0.00 & 0.00 & 0.00 & 0.00 & 0.17 & 0.00 & 0.00 & 0.42 & 0.65 & 3.663 & 0.82 \\
\hline & 3 & 0.00 & 0.08 & 0.00 & 0.00 & 0.00 & 0.22 & 0.00 & 0.00 & 0.05 & 0.05 & 0.00 & 0.18 & 0.00 & 0.00 & 0.00 & 0.24 & 0.00 & 0.00 & 0.15 & 1.09 & 4.300 & 0.74 \\
\hline & 4 & 0.00 & 0.11 & 0.00 & 0.00 & 0.00 & 0.22 & 0.00 & 0.00 & 0.03 & 0.04 & 0.00 & 0.54 & 0.00 & 0.01 & 0.00 & 0.00 & 0.00 & 0.00 & 0.00 & 1.80 & 5.322 & 0.66 \\
\hline & 5 & 0.00 & 0.22 & 0.00 & 0.00 & 0.00 & 0.00 & 0.13 & 0.00 & 0.00 & 0.00 & 0.00 & 0.64 & 0.00 & 0.00 & 0.00 & 0.00 & 0.00 & 0.00 & 0.00 & 3.13 & 6.498 & 0.51 \\
\hline & 6 & 0.00 & 0.42 & 0.00 & 0.00 & 0.00 & 0.00 & 0.28 & 0.00 & 0.00 & 0.00 & 0.00 & 0.28 & 0.00 & 0.00 & 0.00 & 0.00 & 0.00 & 0.00 & 0.00 & 6.43 & 9.194 & 0.30 \\
\hline & 7 & 0.00 & 0.64 & 0.00 & 0.00 & 0.00 & 0.00 & 0.22 & 0.00 & 0.00 & 0.00 & 0.00 & 0.12 & 0.00 & 0.00 & 0.00 & 0.00 & 0.00 & 0.00 & 0.00 & 10.2 & 12.007 & 0.14 \\
\hline & 8 & 0.00 & 0.86 & 0.00 & 0.00 & 0.00 & 0.00 & 0.13 & 0.00 & 0.00 & 0.00 & 0.00 & 0.00 & 0.00 & 0.00 & 0.00 & 0.00 & 0.00 & 0.00 & 0.00 & 14.2 & 14.846 & 0.04 \\
\hline
\end{tabular}




\section{Table 5: NAICS Real Data Restricted Model (50\% Change Restriction)}

This table shows the risk-minimizing combination of sector weightings that produce various levels of returns. In this table weightings are allowed to decrease to no more than $50 \%$ of their current levels. NAICS real data from 1998-2008 are examined. M indicates the minimum variance portfolio. SP indicates the standard deviation on the portfolio. Wt. is the theoretical standard deviation that would occur if each of the sectors were perfectly positively correlated. Red. is the proportion of risk that was eliminated due to portfolio effects. Panel A shows the optimum weightings considering all sectors currently in the economy. Panel B presents the optimal weightings when agriculture is eliminated as a candidate sector. The expected return on the minimum variance portfolio in Panel A is 2.087 percent. The expected return on the minimum variance portfolio in Panel B is 2.174 percent.

\begin{tabular}{|c|c|c|c|c|c|c|c|c|c|c|c|c|c|c|c|c|c|c|c|c|c|c|c|}
\hline \multicolumn{24}{|c|}{ Panel A: Unrestricted Model with All Industries } \\
\hline \multirow{9}{*}{ 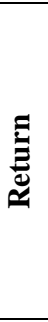 } & & \multicolumn{19}{|c|}{ - } & \multicolumn{3}{|c|}{ Std Dev } \\
\hline & & Ag & Min & Util & Cns & Mfg & Wh & Reta & Tra & Info & Fin & $\mathbf{R E}$ & Sve & Mgt & Ad & Edu & Hlt & Ent & Aco & Gov & $\mathbf{S p}$ & Wt & Red \\
\hline & $\mathrm{M}$ & 0.04 & 0.04 & 0.05 & 0.02 & 0.00 & 0.20 & 0.04 & 0.02 & 0.01 & 0.02 & 0.09 & 0.02 & 0.00 & 0.01 & 0.00 & 0.03 & 0.00 & 0.04 & 0.27 & 0.99 & 4.621 & 0.78 \\
\hline & 0 & 0.05 & 0.00 & 0.12 & 0.02 & 0.03 & 0.01 & 0.04 & 0.02 & 0.01 & 0.02 & 0.09 & 0.02 & 0.31 & 0.01 & 0.00 & 0.03 & 0.00 & 0.04 & 0.10 & 4.11 & 7.301 & 0.43 \\
\hline & 1 & 0.04 & 0.00 & 0.22 & 0.02 & 0.09 & 0.13 & 0.04 & 0.02 & 0.01 & 0.02 & 0.09 & 0.02 & 0.00 & 0.01 & 0.00 & 0.03 & 0.04 & 0.04 & 0.10 & 1.35 & 4.837 & 0.72 \\
\hline & 2 & 0.04 & 0.04 & 0.07 & 0.02 & 0.00 & 0.20 & 0.04 & 0.02 & 0.01 & 0.02 & 0.09 & 0.02 & 0.00 & 0.01 & 0.00 & 0.03 & 0.00 & 0.04 & 0.27 & 0.99 & 4.620 & 0.78 \\
\hline & 3 & 0.03 & 0.08 & 0.00 & 0.02 & 0.00 & 0.21 & 0.04 & 0.02 & 0.01 & 0.02 & 0.09 & 0.21 & 0.00 & 0.01 & 0.00 & 0.03 & 0.00 & 0.04 & 0.10 & 1.28 & 5.300 & 0.75 \\
\hline & 4 & 0.00 & 0.21 & 0.00 & 0.02 & 0.00 & 0.01 & 0.04 & 0.02 & 0.01 & 0.02 & 0.09 & 0.31 & 0.00 & 0.01 & 0.00 & 0.03 & 0.00 & 0.04 & 0.10 & 3.01 & 6.567 & 0.54 \\
\hline & 5 & 0.00 & 0.42 & 0.00 & 0.02 & 0.00 & 0.01 & 0.04 & 0.02 & 0.01 & 0.02 & 0.09 & 0.09 & 0.00 & 0.01 & 0.00 & 0.03 & 0.00 & 0.04 & 0.10 & 6.60 & 9.368 & 0.29 \\
\hline \multicolumn{24}{|c|}{ Panel B: Unrestricted Model Excluding Agriculture } \\
\hline \multirow{10}{*}{ 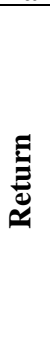 } & & \multicolumn{19}{|c|}{ 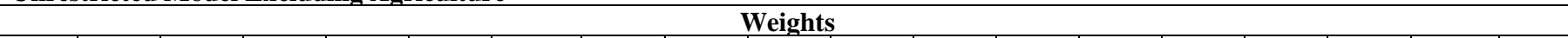 } & \multicolumn{3}{|c|}{ Std Dev } \\
\hline & & Ag & Min & Util & Cns & Mfg & Wh & Reta & Tra & Info & Fin & $\mathbf{R E}$ & Sve & Mgt & Ad & Edu & HIt & Ent & Aco & Gov & Sp & Wt & Red \\
\hline & $\mathrm{M}$ & 0.00 & 0.04 & 0.04 & 0.02 & 0.02 & 0.21 & 0.04 & 0.02 & 0.01 & 0.03 & 0.09 & 0.02 & 0.00 & 0.01 & 0.00 & 0.03 & 0.00 & 0.04 & 0.29 & 1.15 & 4.208 & 0.72 \\
\hline & - & 0.00 & 0.00 & 0.00 & 0.02 & 0.00 & 0.01 & 0.04 & 0.02 & 0.01 & 0.02 & 0.09 & 0.02 & 0.75 & 0.01 & 0.00 & 0.03 & 0.00 & 0.04 & 0.10 & 9.37 & 11.124 & 0.15 \\
\hline & 0 & 0.00 & 0.00 & 0.13 & 0.02 & 0.09 & 0.01 & 0.04 & 0.02 & 0.01 & 0.02 & 0.09 & 0.02 & 0.29 & 0.01 & 0.00 & 0.03 & 0.00 & 0.04 & 0.10 & 4.14 & 6.735 & 0.38 \\
\hline & 1 & 0.00 & 0.00 & 0.22 & 0.02 & 0.13 & 0.14 & 0.04 & 0.02 & 0.01 & 0.02 & 0.09 & 0.02 & 0.00 & 0.01 & 0.00 & 0.03 & 0.03 & 0.04 & 0.10 & 1.51 & 4.467 & 0.66 \\
\hline & 2 & 0.00 & 0.03 & 0.07 & 0.02 & 0.03 & 0.21 & 0.04 & 0.02 & 0.01 & 0.03 & 0.09 & 0.02 & 0.00 & 0.01 & 0.00 & 0.03 & 0.00 & 0.04 & 0.25 & 1.16 & 4.244 & 0.72 \\
\hline & 3 & 0.00 & 0.07 & 0.00 & 0.02 & 0.00 & 0.25 & 0.04 & 0.02 & 0.01 & 0.02 & 0.09 & 0.15 & 0.00 & 0.01 & 0.00 & 0.10 & 0.00 & 0.04 & 0.10 & 1.41 & 4.687 & 0.69 \\
\hline & 4 & 0.00 & 0.20 & 0.00 & 0.02 & 0.00 & 0.01 & 0.04 & 0.02 & 0.01 & 0.02 & 0.09 & 0.32 & 0.00 & 0.01 & 0.00 & 0.03 & 0.00 & 0.04 & 0.10 & 2.96 & 6.487 & 0.54 \\
\hline & 5 & 0.00 & 0.42 & 0.00 & 0.02 & 0.00 & 0.01 & 0.04 & 0.02 & 0.01 & 0.02 & 0.09 & 0.10 & 0.00 & 0.01 & 0.00 & 0.03 & 0.00 & 0.04 & 0.10 & 6.52 & 9.263 & 0.29 \\
\hline
\end{tabular}


Table 6: SIC Data Unrestricted Model

This table shows the risk-minimizing combination of sector weightings that produce various levels of returns. In this table weightings are allowed to take on any value. SIC real data from 1964-1997 are examined. M indicates the minimum variance portfolio. SP indicates the standard deviation on the portfolio. Wt. is the theoretical standard deviation that would occur if each of the sectors were perfectly positively correlated. Red. is the proportion of risk that was eliminated due to portfolio effects. Panel A shows the optimum weightings considering all sectors currently in the economy. Panel B presents the optimal weightings when agriculture is eliminated as a candidate sector. The expected return on the minimum variance portfolio in Panel A is 2.375 percent. The expected return on the minimum variance portfolio in Panel B is 2.781 percent.

\begin{tabular}{|c|c|c|c|c|c|c|c|c|c|c|c|c|c|c|}
\hline \multicolumn{15}{|c|}{ Panel A: Unrestricted Model with All Industries } \\
\hline \multirow{10}{*}{ 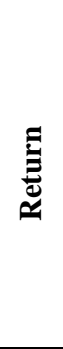 } & & \multicolumn{10}{|c|}{ Weights } & \multicolumn{3}{|c|}{ Std Dev } \\
\hline & & Ag & Min & Const. & Mfg & Trans & Whsl & Retail & Fin Ins RE & Sve & Govt & Sp & Wt STD & Red \\
\hline & $\mathrm{M}$ & 0.055 & 0.014 & 0.000 & 0.030 & 0.047 & 0.107 & 0.026 & 0.096 & 0.000 & 0.625 & 2.730 & 4.755 & 0.426 \\
\hline & -1 & 0.861 & 0.000 & 0.000 & 0.139 & 0.000 & 0.000 & 0.000 & 0.000 & 0.000 & 0.000 & 10.102 & 10.735 & 0.059 \\
\hline & 0 & 0.357 & 0.000 & 0.000 & 0.385 & 0.000 & 0.258 & 0.000 & 0.000 & 0.000 & 0.000 & 6.016 & 8.213 & 0.267 \\
\hline & 1 & 0.180 & 0.000 & 0.000 & 0.202 & 0.000 & 0.350 & 0.000 & 0.000 & 0.000 & 0.268 & 3.703 & 6.082 & 0.391 \\
\hline & 2 & 0.067 & 0.014 & 0.000 & 0.062 & 0.000 & 0.162 & 0.000 & 0.048 & 0.000 & 0.648 & 2.753 & 4.811 & 0.428 \\
\hline & 3 & 0.045 & 0.014 & 0.000 & 0.002 & 0.084 & 0.027 & 0.034 & 0.127 & 0.110 & 0.557 & 2.771 & 4.658 & 0.405 \\
\hline & 4 & 0.005 & 0.008 & 0.000 & 0.000 & 0.084 & 0.000 & 0.000 & 0.153 & 0.396 & 0.354 & 2.996 & 4.351 & 0.312 \\
\hline & 5 & 0.000 & 0.002 & 0.000 & 0.000 & 0.064 & 0.000 & 0.000 & 0.146 & 0.745 & 0.042 & 3.498 & 4.301 & 0.187 \\
\hline
\end{tabular}

Panel B: Unrestricted Model Excluding Agriculture

\begin{tabular}{|c|c|c|c|c|c|c|c|c|c|c|c|c|c|c|}
\hline \multirow{9}{*}{ 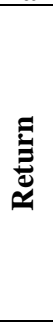 } & & & & & & & ights & & & & & & Std Dev & \\
\hline & & Ag & Min & Const. & Mfg & Trans & Whsl & Retail & Fin Ins RE & Sve & Govt & Sp & Wt STD & Red \\
\hline & $\mathrm{M}$ & 0.000 & 0.012 & 0.000 & 0.058 & 0.049 & 0.116 & 0.000 & 0.124 & 0.000 & 0.642 & 2.786 & 4.454 & 0.375 \\
\hline & 0 & 0.000 & 0.000 & 0.000 & 0.988 & 0.000 & 0.012 & 0.000 & 0.000 & 0.000 & 0.000 & 7.763 & 7.810 & 0.006 \\
\hline & 1 & 0.000 & 0.000 & 0.000 & 0.436 & 0.000 & 0.449 & 0.000 & 0.000 & 0.000 & 0.116 & 4.314 & 5.866 & 0.265 \\
\hline & 2 & 0.000 & 0.010 & 0.000 & 0.129 & 0.000 & 0.198 & 0.000 & 0.026 & 0.000 & 0.637 & 2.861 & 4.472 & 0.360 \\
\hline & 3 & 0.000 & 0.012 & 0.000 & 0.033 & 0.073 & 0.052 & 0.000 & 0.142 & 0.105 & 0.584 & 2.808 & 4.411 & 0.364 \\
\hline & 4 & 0.000 & 0.008 & 0.000 & 0.000 & 0.085 & 0.000 & 0.000 & 0.157 & 0.387 & 0.364 & 2.996 & 4.315 & 0.306 \\
\hline & 5 & 0.000 & 0.002 & 0.000 & 0.000 & 0.064 & 0.000 & 0.000 & 0.146 & 0.745 & 0.042 & 3.498 & 4.301 & 0.187 \\
\hline
\end{tabular}




\section{Table 7: SIC Nominal Data Restricted Model (50\% Change Restriction)}

This table shows the risk-minimizing combination of sector weightings that produce various levels of returns. In this table weightings are allowed to decrease to no more than $50 \%$ of their current levels. SIC real data from 1964-1997 are examined. M indicates the minimum variance portfolio. SP indicates the standard deviation on the portfolio. Wt. is the theoretical standard deviation that would occur if each of the sectors were perfectly positively correlated. Red. is the proportion of risk that was eliminated due to portfolio effects. Panel A shows the optimum weightings considering all sectors currently in the economy. Panel B presents the optimal weightings when Agriculture is eliminated as a candidate sector. The expected return on the minimum variance portfolio in Panel A is 2.917 percent. The expected return on the minimum variance portfolio in Panel B is 3.021 percent.

\begin{tabular}{|c|c|c|c|c|c|c|c|c|c|c|c|c|c|c|}
\hline \multicolumn{15}{|c|}{ Panel A: Unrestricted Model with All Industries } \\
\hline \multirow{6}{*}{ 窇 } & & \multicolumn{10}{|c|}{ Weights } & \multicolumn{3}{|c|}{ Std Dev } \\
\hline & & Ag & Min & Const. & Mfg & Trans & Whsl & Retail & Fin Ins RE & Svc & Govt & Sp & Wt STD & Red \\
\hline & $\mathrm{M}$ & 0.046 & 0.013 & 0.021 & 0.014 & 0.052 & 0.025 & 0.055 & 0.111 & 0.111 & 0.551 & 2.856 & 4.781 & 0.403 \\
\hline & 2 & 0.167 & 0.001 & 0.021 & 0.149 & 0.052 & 0.212 & 0.055 & 0.111 & 0.111 & 0.121 & 3.807 & 6.271 & 0.393 \\
\hline & 3 & 0.035 & 0.013 & 0.021 & 0.014 & 0.075 & 0.020 & 0.055 & 0.111 & 0.111 & 0.545 & 2.863 & 4.728 & 0.394 \\
\hline & 4 & 0.006 & 0.007 & 0.021 & 0.014 & 0.061 & 0.020 & 0.055 & 0.117 & 0.421 & 0.279 & 3.161 & 4.495 & 0.297 \\
\hline \multicolumn{15}{|c|}{ Panel B: Unrestricted Model Excluding Agriculture } \\
\hline \multirow{6}{*}{ 茪 } & & \multicolumn{10}{|c|}{ Weights } & \multicolumn{3}{|c|}{ Std Dev } \\
\hline & & Ag & Mining & Const. & Mfg & Trans & Whsl & Retail & Fin Ins RE & Svc & Govt & Sp & Wt STD & Red \\
\hline & M & 0.000 & 0.011 & 0.021 & 0.034 & 0.052 & 0.038 & 0.055 & 0.111 & 0.111 & 0.567 & 2.902 & 4.468 & 0.350 \\
\hline & 2 & 0.000 & 0.001 & 0.021 & 0.425 & 0.052 & 0.115 & 0.055 & 0.111 & 0.111 & 0.110 & 4.425 & 6.082 & 0.272 \\
\hline & 3 & 0.000 & 0.010 & 0.021 & 0.041 & 0.052 & 0.043 & 0.055 & 0.111 & 0.111 & 0.556 & 2.903 & 4.490 & 0.354 \\
\hline & 4 & 0.000 & 0.006 & 0.021 & 0.014 & 0.063 & 0.020 & 0.055 & 0.121 & 0.410 & 0.290 & 3.157 & 4.452 & 0.291 \\
\hline
\end{tabular}


The results for the NAICS data are presented in Table 5. In the same manner as used above, Panel A considers all sectors of the economy. In Panel B, the agriculture sector is assigned a weighting of zero. A similar result to Table 4 holds in Table 5. That is, relating to our theoretical model and the corollary 2 , it suggests that the social planner should target a 2 percent real growth rate. The careful reader will notice that the number of potential returns is less in Table 5 than Table 4. In Table 4, returns of 8 percent were achievable while in Table 5 the maximum return is 5 percent. This finding is not surprising as elimination of a sector reduces the number of portfolio combinations that can be achieved.

Tables 6 and 7 repeat the above analysis using a longer, historical time series. Table 6 contains the unrestricted results, allowing changes in weightings of any magnitude. The risk-minimizing portfolio eliminates the services and construction industries, with the government sector composing 62.5 percent of the economy. When agriculture is eliminated from the economy, the weighting of agriculture is primarily reallocated to manufacturing. In the case of a one percent expected return, the weighting of manufacturing increases from 20 percent to 43 percent of the economy when agriculture is eliminated.

Table 7 is the restricted model that allows for a maximum of a 50 percent change in any sector. In each case, the results are presented for the current slate of sectors, and considering the elimination of the agriculture industry. Here the feasible set of expected returns range from only 2 to 4 percent. Again, the elimination of agriculture generally involves an increase in weighting of the manufacturing sector.

The careful reader will notice that the longer time frame dataset examined in Tables 6 and 7 produce a narrower band of returns than the shorter time frame datasets examined in Tables 4 and 5. For example Table 4, Panel A shows returns ranging from -2 to 8 percent. On the other hand, the corresponding results from Table 6 show a range of -1 to 5 percent. This is an interesting result, suggesting a significant element of time diversification. The findings indicate that time heals many wounds, even in the economy.

To further demonstrate the findings, the risk, return relationships are graphically charted. Figure 1 and 2 show the relationship for the NAICS and SIC data respectively. Each line in the graph represents the results from one panel in Tables 4-7. The minimum variance portfolio occurs at that point closest to the vertical axis. Other points on the graph represent other risk return combinations. For any standard deviation level, points that graph above the minimum variance portfolio dominate points that graph below the minimum variance portfolio. In each case the figure shapes are consistent with those commonly found in portfolio analysis. Figure 2 however shows far less curvature on the top side of the graph. In general, the results suggest sensible growth goals would seem to be between two and five percent.

\section{VI: CONCLUSION}

In this paper we introduce and empirically demonstrate a new model of economic development that we call Portfolio Economic Development. Our approach focuses on the risk-return nature of development projects. The paper examines how the loss of a dominant industry group in an economy causes significant economic problems and how those problems might be mitigated by developing the economy in a portfolio context. Using data from Hawaii, we are able to demonstrate how the optimal weightings in an economy change with the loss of a sector. In addition, we demonstrate the loss in diversification potential associated with the loss of a major industry.

The approach may help planners select optimal mixes of projects for development of any economy going through a transitional period. Planners can also use the results to prepare and respond to the loss of a dominant industry group. The empirical analysis here is limited to the State of Hawaii. Future research might include data from other states as well as other countries to obtain additional insights. Future research might also model the probability of particular shocks occurring and the potential impact on differing sectors. 
Figure 1: Risk Return Tradeoff, NAICS Data From 1997-2008

This figure shows the risk and return tradeoff for the NAICS Portfolios using real data from 1997-2008. NAICS UNRES, NAICS UNRES W/O AG, NAICS RES and NAICS RES W/O AG indicate the unrestricted portfolio, unrestricted portfolio without agriculture, fifty percent reduction limit portfolio and fifty percent reduction limit portfolio without agriculture respectively.

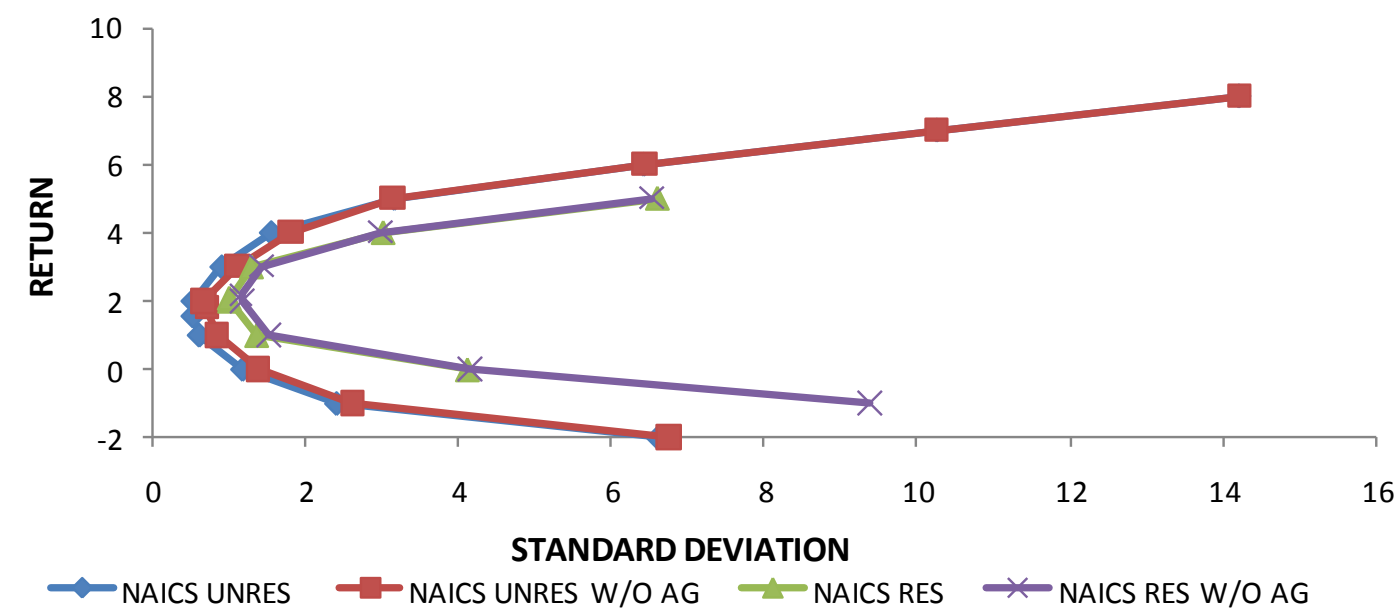

Figure 2: Risk Return Tradeoff, SIC Data From 1963-1997

This table shows the risk and return tradeoff for the SIC Portfolios using real data from 1963-1997. SIC UNRES, SIC UNRES W/O AG, SIC RES and SIC RES W/O AG indicate the unrestricted portfolio, unrestricted portfolio without agriculture, fifty percent reduction limit portfolio and fifty percent reduction limit portfolio without agriculture respectively.
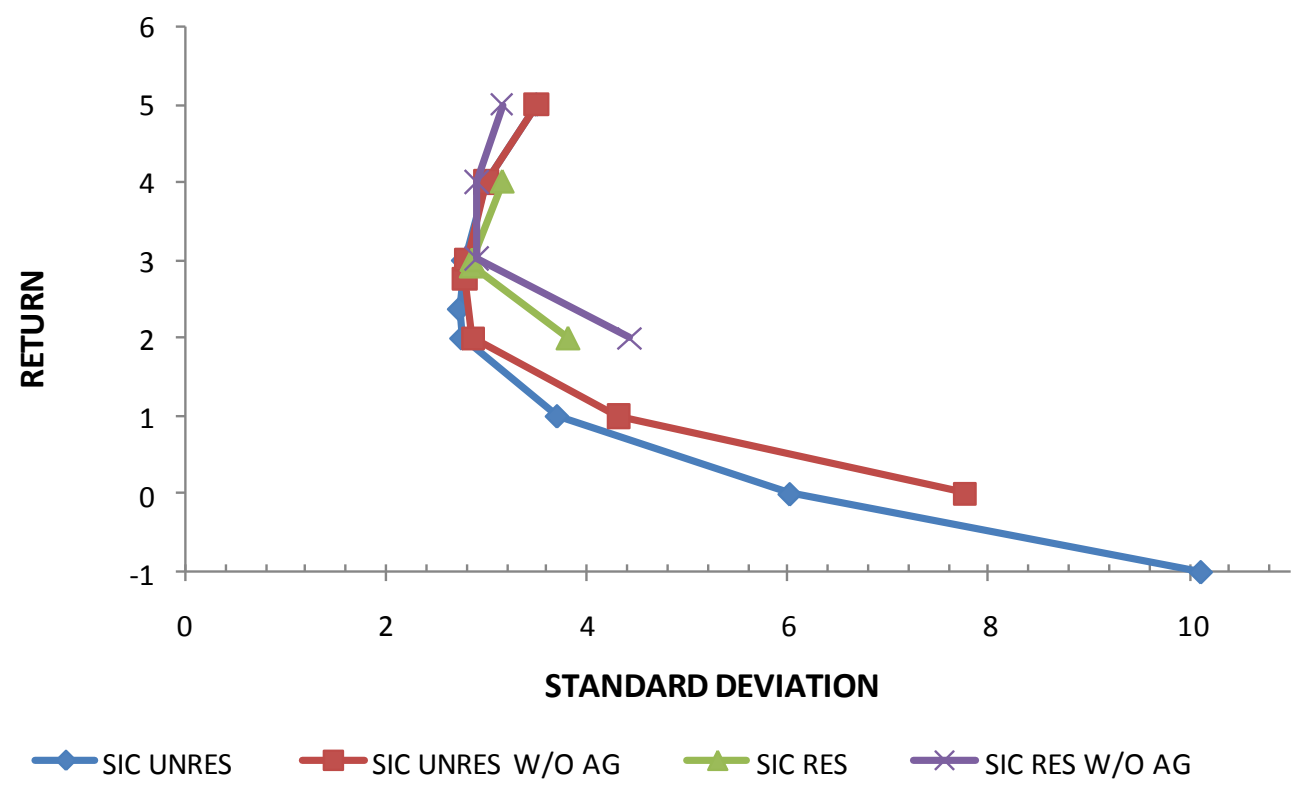


\section{ACKNOWLEDGEMENT}

The authors would like to thank an anonymous reviewer for helpful comments.

\section{AUTHOR INFORMATION}

Tam Bang Vu, College of Business and Economics, University of Hawaii, Hilo, Hawaii, USA. Email: tamv@hawaii.edu. Her recent publications are with Journal of International Financial Markets, Institutions \& Money, Applied Economics, and Applied Economics Letters.

Terrance Jalbert is Professor of Finance at University of Hawaii Hilo. His recent publications appear in journals such as Financial Services Review, International Journal of Finance, Journal of Emerging Markets and Journal of Accounting Education. He can be reached at University of Hawaii Hilo, COBE, 200 West Kawili St., Hilo, HI, 96720, USA. Email: jalbert@hawaii.edu.

David Hammes, College of Business and Economics, University of Hawaii, Hilo, Hawaii, USA. Email: hammes@ hawaii.edu. His recent publications are with The Philosophy of the Social Sciences, (forthcoming), The Journal of the History of Economic Thought, Econometric Theory, The Encyclopedia of Business Ethics and Society, the Journal of Business \& Economic Research, and the Journal of Economic Studies.

\section{ENDNOTES}

(1) In the 1980s and 1990s almost all commercial sugar cane growing was on the Big Island of Hawaii and sugar was the main agricultural crop.

(2) Lucas (1978), .pp. 1430-1431.

(3) In the same way that in portfolio theory the size of any given portfolio is assumed small relative to the market (thus not changing relative prices), we assume that our economies - stimulated by the experience of Hawaii in the $1980 \mathrm{~s} / 1990$ s - are small relative to the global 'economy' and thus refer to them as 'islands', which can be literal or figurative as the case requires.

(4) The initials stand for Rural Economic Transition Assistance-Hawaii . It started in 1993/1994. We drop the H in what follows.

(5) Among these economic factors: low world prices of sugar, rising costs of land and labor in the Hawaiian industry, low-cost substitute sweeteners, e.g. sugar beats andcorn--which could be turned into corn-based sweeteners, and development of artificial--lower calorie--sweeteners, to name but a few.

(6) This was about $2 \%$ to $3 \%$ of the employed labor force on the Big Island in those years.

(7) For a recent approach to measuring the cost of output variability in a theoretical framework see Kiley, 2003.

(8) See, for example, Stockman, Alan, Macroeconomics, $2^{\text {nd }}$. Ed., 1999, Dryden Press, pps. 369-370.

(9) For a proof of this result, please see appendix A.

(10) For the cautionary saving motive, please see Romer (2003), Chapter 7.

(11) Please see Appendix B for the derivation.

(12) The analysis is conducted by using the Premium Excel Solver upgrade product available from Frontline Systems, Inc.

\section{AUTHOR INFORMATION}

Tam Bang Vu, College of Business and Economics, University of Hawaii, Hilo, Hawaii, USA. Email: tamv@hawaii.edu. Her recent publications are with Journal of International Financial Markets, Institutions \& Money, Applied Economics, and Applied Economics Letters.

Terrance Jalbert is Professor of Finance at University of Hawaii Hilo. His recent publications appear in journals such as Financial Services Review, International Journal of Finance, Journal of Emerging Markets and Journal of Accounting Education. He can be reached at University of Hawaii Hilo, COBE, 200 West Kawili St., Hilo, HI, 96720, USA. Email: jalbert@hawaii.edu. 
David Hammes, College of Business and Economics, University of Hawaii, Hilo, Hawaii, USA. Email: hammes@ hawaii.edu. His recent publications are with The Philosophy of the Social Sciences, (forthcoming), The Journal of the History of Economic Thought, Econometric Theory, The Encyclopedia of Business Ethics and Society, the Journal of Business \& Economic Research, and the Journal of Economic Studies.

\section{REFERENCES}

1. Acemoglu, D. and F. Zilibotti, 1997, "Was Prometheus Unbound by Chance? Risk, Diversification and Growth," Journal of Political Economy 105 (4): 709-751.

2. Bauer P.T., 1981, Equality, the Third World, and the Economic Delusion, Boston: Harvard University Press.

3. Bezemer, D (editor), 2006, On Eagle's Wings: The Albanian Economy in Transition, NY: Nova Science Publishers, Inc.

4. Cass, D., 1965, "Optimum Growth in an Aggregative Model of Capital Accumulation," Review of Economic Study, 32 (July): 233-240.

5. Department of Foreign Affairs and Trade, 2000, Transforming Thailand: Choices for the New Millenium, AEEU: Pacific Power.

6. Domar, E.D., 1946, "Capital Expansion, Rate of Growth, and Employment," Econometrica 14: 137-147.

7. Friedman, M., 1957, A Theory of the Consumption Function, New Jersey: Princeton University press.

8. Hahn, YK and Associates, 2002, "Economic and Social Impact of the RETA-H Program: Final Report" Report Prepared for the Small Business Development Center Network.

9. Hall, R. E., 1978, "Stochastic Implications of Life Cycle-Permanent Income Hypothesis: Theory and Evidence," The Journal of Political Economy, Vol. 86, No. 6, December, 971-987.

10. Hansen, L.P., and K. Singleton, 1983, Stochastic Consumption, Risk Aversion, and the Temporal Behavior of Asset Returns," Journal of Political Economy, 91 (2): 249-265.

11. Harrod, R.F., 1939, "An Essay in Dynamic Theory," Economic Journal 49: 14-33

12. Kiley, Michael T., 2003 "An Analytical Approach to the Welfare Cost of Business Cycles and the Benefit from Activist Monetary Policy," Contributions to Macroeconomics: Vol. 3: Iss. 1, Article 4. Available at: http://www.bepress.com/bejm/contributions/vol3/iss1/art4

13. Krugman, P., 2001, The Return of Depression Economics. New York: Norton \& Company.

14. Kuznet S., 1950, "International Differences in Income Levels Reflections on Their Causes," Boletin Banco Central de Venezuela.

15. Lal D.K., 1985, The Poverty of "Development Economics," Massachusetts: Harvard University Press.

16. Levy, H. and H.M. Markowitz, 1979, "Approximating Expected Utility by a Function of Mean and Variance," The American Economic Review, 69 (3): 308-317.

17. Lewis, A., 1954, "Economic Development with Unlimited Supplies of Labor," Manchester School, May: 132-176.

18. Lucas, R.F., Jr., 1978, “Asset Prices in an Exchange Economy,” Econometrica, 46 (November): 14291445.

19. Mankiw, N. G., 1982, "Hall's Consumption Hypothesis and Durable Goods," Journal of Monetary Economics, 10 (1982) 417-425.

20. Markowitz, H.M., 1952, "Portfolio Selection," Journal of Finance, 7 (1): 77-91.

21. Markowitz, H.M., 1991, "Foundations of Portfolio Theory," The Journal of Finance, 50 (2): 469-477.

22. Martins, O.J. and R.Ahrend, 2003, OECD Economic Surveys, 2001-2002, Romania: Organizarion for Economic Cooperation and Development.

23. Merton, R.C., 1973, “An Intertemporal Capital Asset Pricing Model,” Econometrica, 41 (September):

24. Mobarak, A. M., 2005, "Democracy, Volatility and Economic Development," The Review of Economics and Statistics 87 (2): 348-361.

25. Modigliani, F., 1971, "Monetary Policy and Consumption," in Consumer Spending and Monetary Policy: The Linkages, Conference Series No. 5, Massachusetts: Federal Reserve Bank of Boston, 1971.

26. Nurkse R., 1961, Equilibrium and Growth in the World Economy: Economic Essays, Boston: Havard University Press.

27. Prebisch, R., 1976, "A Critique of Peripheral Capitalism," United Nations Commission for Latin America Review, New York: United Nation. 
28. Prichett, L., 2000, "Understanding Patterns of Economic Growth: Searching for Hills among Plateaus, Mountains and Plains," World Bank Economic Review, 14: 221-250.

29. Ramey, G., and V. Ramey, 1995, "Cross-Country Evidence on the Link Between Volatility and Growth," American Economic Review, 85(5):1138-1151.

30. Ramsey F.P., 1928, “A Mathematical Theory of Saving,” Economic Journal, 38: (December): 543-559.

31. Roll, R., 1977, “A Critique of the Asset Pricing Theory’s Tests,” Journal of Financial Economics, vol. 4 (March), 129-176.

32. Romer, D., 2003, Advanced Macroeconomics, Massachusetts: McGraw-Hill.

33. Rubinstein, M., 1976, "The Valuation of Uncertain Income Streams and the Pricing of Options," Bell Journal of Economics, 7 (Autumn): 407-425.

34. Sharpe, W.F., 1963, “A Simplified Model for Portfolio Analysis,” Management Science, 9 (2): $277-293$.

35. Sharpe, W.F., 1964, Capital Asset Price: A Theory of Market Equilibrium under Condition of Risk," Journal of Finance, 19 (3): 425-442.

36. Singer, H., 1964, International Development, Growth and Change, New York: Mcgraw-Hill Book Co.

37. Solow R.M., (1956), “A Contribution to the Theory of Economic Growth," Quarterly Journal of Economics, 70 (February): 65-94.

38. St John, R.B., 2006, Revolution, Reform and Regionalism in Southeast Asia, London and New York: Routledge.

39. Stiglitz J., 2002, Globalization and Its Discontents, London: The Penguin Press.

40. Stockman, Alan, Macroeconomics, $2^{\text {nd }}$. Ed., Dryden Press, 1999.

41. Swan, T.W., 1956, "Economic Growth and Capital Accumulation," Economic Record 32 (November): $334-$ 361 .

42. Tang, L.H., and L.H. Nhac, 2002, Nghien cuu so sanh doi moi kinh te o Viet Nam va cai cach kinh te o Trung Quoc, Hanoi: Nha xuat ban chinh tri quoc gia.

43. Tobin, J., 1958, "Liquidity Preference as Behavior towards Risk," The Review of Economic Studies, 25: 6586. 


\section{APPENDIX A: THE CONSUMER}

Maximize $E_{0} W=E_{0} \int_{t=0}^{\infty} e^{-\rho t} U_{t}\left[K_{t}\left(C_{t}\right)\right] d t$

subject to $\dot{A}_{t}=w_{t}-\dot{K}_{t}-\delta K_{t}+r A_{t}$

and $K_{t} \equiv-\delta K_{t}+C_{t}$

From (3)

$C_{t}=\dot{K}_{t}+\delta K_{t}$

Combining (2) and (4) yields

$\dot{A}_{t}=w_{t}-C_{t}+r A_{t}$

Thus, the current Hamiltonian is

$H_{c}=E_{0} U\left[K_{t}\left(C_{t}\right)\right]+\lambda\left(w_{t}-C_{t}+r A_{t}\right)$

The first order condition is

$\frac{\partial H_{c}}{\partial C_{t}}=0 \rightarrow E_{0} U^{\prime}\left(C_{t}\right)=E_{0} U^{\prime}\left(K_{t}\right) \frac{\partial K}{\partial C}=\lambda$
$\dot{\lambda}=-\frac{\partial H_{c}}{\partial A_{t}}+\lambda \rho \rightarrow-\frac{\dot{\lambda}}{\lambda}=r-\rho$

and the tranversality condition

$\lim _{t \rightarrow \infty} A U^{\prime}\left(C_{t}\right) e^{-\rho t}=0$

From (7)

$$
\lambda=E_{0} e^{\ln U^{\prime}\left(C_{t}\right)}
$$

assume that $\ln U^{\prime}$ is normally distributed with mean $E_{o} \ln U^{\prime}$ and variance $v$, then

$$
\lambda=e^{E_{o} \ln U^{\prime}+(v / 2) t}
$$

$\ln \lambda=E_{o} \ln U^{\prime}+\frac{v}{2} t$

$-\frac{\dot{\lambda}}{\lambda}=-E_{o} \frac{U^{\prime \prime} C}{U^{\prime}} \frac{\dot{C}}{C}-\left(\frac{v}{2}\right)=\theta E_{o} \frac{\dot{C}}{C}-\frac{v}{2}$ 
Combining (8) and (10) yields

$\theta E_{o} \frac{\dot{C}}{C}=\frac{v}{2}+r-\rho$

(A11)

$E_{o} \frac{\dot{C}}{C}=\frac{1}{\theta}\left(\frac{v}{2}+r-\rho\right)$

\section{APPENDIX B: FROM CONSUMPTION TO OUTPUT}

To convert this model to the output version, we use Equation (5) in the text:

$C_{t}=\alpha Y_{t}$

where $\alpha$ is the marginal propensity to consume and $Y$ is output(B1)

Taking the logs of both sides yields

$\ln C_{t}=\ln \alpha+\ln Y_{t}$

Differentiating both sides with respect to time to obtain

$$
\frac{\dot{C}_{t}}{C_{t}}=\frac{\dot{Y}_{t}}{Y_{t}}
$$

Hence, the left hand side expression of (B3) is the same as that in Equation (4). Repeating the same process, we will have the right hand side expression similar to that in Equation (4) with $\sigma$ as the variance of output. With the assumption that the rate of social time preferences equals the interest rate, the two terms cancel out, and we have Equation (6) in the text. 


\section{NOTES}

